\title{
O ENSINO DE HISTÓRIA EM TEMPOS DE CONSERVADORISMOS: ALGUNS DESAFIOS NA FORMAÇÃO DE PROFESSORES
}

\section{HISTORY TEACHING IN CONSERVATIVE TIMES: SOME CHALLENGES IN THE TEACHER TRAINING}

\author{
Pâmella Santos dos Passos ${ }^{1}$ \\ Luciana de Sá Guigues Almeida
}

\begin{abstract}
RESUMO
Este artigo é fruto de uma pesquisa de iniciação científica que tem por objetivo tecer reflexões acerca do ensino de História em tempos de conservadorismo e elaborar táticas de superação desse fenômeno em sala de aula. Inicialmente, buscamos situar o leitor no que identificamos como avanço do conservadorismo no Brasil na atual conjuntura, evidenciando seus impactos negativos na educação brasileira. Em seguida, discorremos sobre o curso voltado para licenciandos que se originou da pesquisa. Analisamos principalmente as respostas dos formulários de inscrição e de avaliação do mesmo, buscando afirmar o papel do diálogo e do afeto no ensino de História, em especial a partir das elucubrações de Paulo Freire acerca da importância de uma educação dialógica e libertadora.
\end{abstract}

\section{PALAVRAS CHAVE}

Ensino de História; Conservadorismo; Formação de Professores; Afeto.

\begin{abstract}
The present article results from an undergraduate research that aims to reflect on the History teaching in conservative times and to develop tactics to overcome this issue in the classrooms. At first was presented what we identified as the advancing of conservatism in Brazil nowadays, highlighting its negative impacts on the national education. Then, we discussed about the course for undergraduates that was originated from the research. We mainly analyzed the student's responses of the registration and evaluation forms, seeking to affirm the role of dialogue and affection in the history teaching, especially based on the explanations of Paulo Freire about the importance of a dialogical and liberating education.
\end{abstract}

\footnotetext{
${ }^{1}$ Professora do quadro efetivo do Instituto Federal de Educação Ciência e Tecnologia do Rio de Janeiro (IFRJ). Atualmente realiza estágio de Pós Doutorado no Programa de Pós Graduação em Educação da Universidade Federal Fluminense (UFF). Doutora em História Social pela Universidade Federal Fluminense (2013). Possui experiência na área de História e Ensino de História, com ênfase em História do Brasil República.

${ }^{2}$ Licencianda em História na Universidade Federal Fluminense (UFF). Atualmente Bolsista de Iniciação Científica pelo CNPq em projeto realizado no Instituto Federal de Educação, Ciência e Tecnologia do Rio de Janeiro (IFRJ).
} 


\section{KEYWORDS}

History teaching; Conservatism; Teacher training; Affection.

\section{Introdução}

Vale a pena pesquisar em tempos de desincentivo e desqualificação das investigações acadêmicas? Tal pergunta permeou nossas reflexões desde o início da elaboração do projeto $^{3}$ que deu origem a este artigo em 2019, ano no qual assistimos a um desmonte da pesquisa brasileira com corte em programas e investimentos aos órgãos como CNPq e CAPES. Para uma parte importante do discurso oficial, as Universidades brasileiras não fazem pesquisa e os institutos federais, local no qual esta pesquisa está sendo desenvolvida, devem limitar-se à formação profissional. Nessa conjuntura de ataques nos cabe escolher recuar, paralisar ou seguir. A resposta encontrada veio através do autor Walter Benjamin em seu conhecido texto sobre o conceito da história:

O dom de despertar no passado as centelhas da esperança é privilégio exclusivo do historiador convencido de que também os mortos não estarão em segurança se o inimigo vencer. E esse inimigo não tem cessado de vencer. (1994, p. 224).

Como historiadoras, escolhemos seguir despertando centelhas de esperança. Nesse sentido, o que trazemos nesta comunicação são discussões, ainda que iniciais, do projeto de pesquisa intitulado "A Batalha de Clio: narrativas do Ensino de História em tempos sombrios". Tal projeto busca historicizar processos de negação aos conhecimentos científicos e acadêmicos compreendendo-os como base do conservadorismo que vivenciamos no momento. A esse respeito, Henri Acserlrad, reconhecido pesquisador e professor da UFRJ nos esclarece:

O projeto anti-democrático que naturaliza e justifica a distribuição das pessoas segundo status desiguais - expressão explícita do conservadorismo brasileiro - costuma recusar o debate intelectual quando este se aplica à busca de superação das desigualdades. Tendências anti-intelectualistas deste tipo têm aparecido, por exemplo, nos ataques feitos às ciências humanas, tidas por inúteis, e à universidade pública em geral, por esta abrigar pesquisas que questionam a reprodução da sociedade tal como ela é. Combatem, por vezes, o princípio mesmo da democracia que garante a legitimidade do debate sobre

\footnotetext{
${ }^{3} \mathrm{O}$ referido projeto contou com uma bolsa de Iniciação Científica do CNPq e auxílio financeiro do IFRJ através do edital Prociência.
} 
o que é legítimo e o que é ilegítimo, princípio que permitiu, até aqui, que movimentos sociais tivessem podido oferecer resistência à imposição de desigualdades sociais, de gênero e de raça. (ACSERLRAD, LE MONDE DIPLOMATIQUE BRASIL, 2018)

O anti-intelectualismo de que nos fala o autor chega às escolas e às salas de aula na forma de desqualificação e censura de determinados conteúdos programáticos. No que tange ao campo da história podemos citar temas como: Escravidão, Movimentos Revolucionários de Esquerda, Ditaduras, Direitos Humanos dentre outros, nos quais o consolidado trabalho de pesquisas historiográficas é renegado sob a justificativa de que "há visões diferentes sobre o assunto".

Cabe aqui explicar o título escolhido para a pesquisa. Usando a mitologia grega, trazemos a imagem de Clio, filha de Zeus com Mnemosine, em batalha. Conhecida por ser a musa da história e da criatividade, tal figura mitológica nos inspira a articular criatividade e história em nossa sobrevivência frente aos ataques e descréditos direcionados aos saberes históricos e ao ofício do historiador que no caso brasileiro atual, são orquestrados pelo Movimento Escola Sem Partido (ESP) ${ }^{4}$.

Elaborando notícias falsas e distorcendo realidades, o discurso propagado pelo ESP dialoga com um público de caráter fortemente religioso de cunho fundamentalista que acredita que abordar na escola temas como: partes íntimas, assédio sexual e prazer são um perigo as crianças e jovens. Contrariando estudos que comprovam que o debate de gênero no espaço escolar é um importante meio para identificação de violações e abusos, o ataque a questão de gênero promovido pelo ESP produz medo e pânico.

$\mathrm{O}$ medo produzido por tais discursos leva ao ódio, sentimento este identificado e analisado pelo professor Fernando Penna em seu artigo denominado $O$ ódio aos professores (2016). Este artigo corrobora com a visão de que uma das plataformas políticas da ascensão conservadora é a construção de uma cultura do medo, e também do ódio, processo esse que o Brasil vivenciou no recente processo eleitoral ocorrido em 2018.

O país assistiu à construção de uma cultura do medo e do ódio que possibilitou a vitória de diversos políticos de extrema direita nas diferentes esferas de poder da nação. Neste contexto o discurso conservador identificou a potencialidade da criação de um

\footnotetext{
${ }^{4}$ Maiores informações sobre o movimento estão disponíveis no link http://escolasempartido.org/ Acesso em 06/05/2020.
} 
inimigo, e este inimigo é o professor doutrinador, em geral, da área de História e/ou Ciências Humanas lotado na educação pública, espaço este que, mesmo sucateado, ainda é lócus de resistência e criticidade frente às redes privadas, que pela relação mercadológica que estabelece com seus profissionais, exercem uma censura de conteúdo, por vezes não explícita.

E aqui podemos estabelecer um parâmetro com outro momento histórico: o da construção de uma cultura do medo, baseado no discurso anticomunista, no período da Guerra Fria. Ao abordar a importância econômica desse conflito ideológico, Arrighi ressalta o caráter ficcional dessa guerra, chegando a empregar o termo "invenção" da Guerra Fria. Para o autor, o medo produzido pelo confronto entre comunismo e capitalismo conseguiu o que os cálculos de custo-benefício não tinham como conseguir, ou seja, a produção do medo do comunismo era bem mais lucrativa que muitas medidas estritamente econômicas (1996, p.305).

Compartilhamos das reflexões propostas por Arrighi, pois identificamos que, assim como os "inventores" da Guerra Fria tinham interesses financeiros, os anticomunistas semeavam o medo não somente por sua ojeriza ao comunismo e seus adeptos, mas também por interesses econômicos (PASSOS, 2017, p.32).

Tal sentimento anticomunista persistiu e ressoa na construção do ESP. Miguel Nagib, fundador do movimento, articula um discurso, no qual, desqualifica "o trabalho complexo de pensadores importantes através do recurso não da crítica, mas da calúnia e da difamação de cunho pessoal" (PENNA, 2016, p. 96). Criaram-se espantalhos, como o pensador brasileiro reconhecido internacionalmente, Paulo Freire, que é constantemente achincalhado pelo movimento. Segundo Fernando Penna, professor que se dedica a compreender o fenômeno político do Escola Sem Partido,

uma imagem compartilhada no perfil público do criador do Escola Sem Partido, mostrando suposto vampiro em um caixão, vem acompanhada do comentário: "Conde Gramsci, o vampiro que vampiriza a educação brasileira, com a ajuda de Paulo Nosferatu Freire, pode estar com seus dias contados (2016, p. 96).

As imagens utilizadas no exemplo acima nos remetem a noticiários das décadas de 1930 e 1960 no Brasil, períodos de forte propaganda anticomunista que teve por 
finalidade legitimar o golpe do Estado Novo em 1937 e o golpe dos militares em 1964. Recorrendo a estas imagens míticas o ESP atualiza o discurso anticomunista tão fortemente presente no imaginário popular brasileiro. Essa metodologia discursiva foi muito comum no contexto da Guerra Fria, no Brasil dos anos 1960. Podemos citar o exemplo do Instituto de Pesquisa e Estudos Sociais, o IPES,

\begin{abstract}
tal Instituto atuava produzindo e divulgando o anticomunismo. Ou seja, dando visibilidade a uma dada comunidade de sustentação, que possui uma identidade anticomunista, ao mesmo tempo que produzia tal identidade nos coenunciadores de seus materiais. Em prol de uma suposta luta contra o comunismo, discursos foram produzidos, construindo um cenário de combate ao comunismo, atualizando cenografias, com o objetivo de ganhar adeptos (PASSOS, 2017, p.70).
\end{abstract}

Em nossa hipótese, esta mesma estratégia é utilizada hoje pelo movimento ESP, no qual os comunistas são os professores doutrinadores apresentados como inimigos públicos da nação. O medo, atualizado por um anticomunismo brasileiro quase centenário, cria uma espécie de "cordão sanitário", típico da ordem bipolar, que busca isolar uma educação crítica, que discursivamente é apresentada como parcial e por isso maculada. Frente a esta educação problematizadora e produtora de autonomia apresentase uma proposta de educação neutra, transmissora de conteúdos e não doutrinadora.

É nesse atual contexto que lecionamos a disciplina de História para turmas do Ensino Médio Técnico Integrado ao Ensino Profissional no Campus Rio de Janeiro do IFRJ, local onde também recebemos estagiários de licenciatura em História, em especial alunos da Universidade Federal Fluminense, cursando a disciplina de Pesquisa e Prática de Ensino (PPE).

A relação com esses alunos-mestres se dá com intenso diálogo e coprodução, pois como afirma Guimarães Rosa "Mestre não é quem sempre ensina, mas quem de repente aprende". Fruto da parceria estabelecida com o Laboratório de Ensino de História da Universidade Federal Fluminense (LEH-UFF) o encontro com estagiários nos possibilitou inúmeras atividades como: visitas técnicas, apresentação de trabalho em congressos, elaboração de material conjunto, diálogos sobre incertezas e inseguranças.

Assim, em tempos de acirramento do conservadorismo propomos com este projeto fortalecer esta parceria transformando-a em uma pesquisa acadêmica conjunta, pois frente aos ataques sofridos "ninguém solta a mão de ninguém". 
Segundo relatório da Anistia Internacional publicado em $2017^{5}$ o Brasil é o país das Américas que mais mata defensores de Direitos Humanos. Agregada a esta triste realidade, temos os índices de violência contra a população LBGT que aumentam significativamente. De acordo com o levantamento feito pelo Grupo Gay da Bahia, os casos de homicídios LGBTs aumentaram 30\% em $2017^{6}$.

Outra absurda e vergonhosa estatística diz respeito ao extermínio da juventude negra no país. Também, segundo dados da Anistia Internacional, dos 56 mil homicídios que ocorrem por ano no Brasil, mais da metade são entre os jovens. E dos que morrem, $77 \%$ são negros ${ }^{7}$.

Tais dados refletem uma sociedade intolerante e sem respeito à diversidade. Nesse contexto o papel da educação, em especial da escola, assume importância fundamental para alteração desta realidade. No entanto, o que assistimos é o discurso conservador concentrando forças para impedir exatamente tais debates na educação, em especial no espaço escolar.

A esse respeito, os pesquisadores José Antonio Sepúlveda e Denize Sepúlveda em artigo intitulado $O$ pensamento conservador e sua relação com práticas discriminatória na educação: a importância da laicidade (2016) apontam os perigos e desdobramentos desta onda conservadora no campo educacional. Como identificam os autores, o conservadorismo presente na educação atua como fator de exclusão social, pois este se atualiza em práticas discriminatórias que segregam as diferenças.

Nesse sentido, o projeto do qual resultou este artigo, ao abordar o discurso conservador e sua relação de negação da História, em sua dimensão de pesquisa historiográfica, bem como ao produzir narrativas e materiais de superação dos medos e conservadorismos atua diretamente na defesa da educação como um espaço de práticas inclusivas e não discriminatórias.

Em tempos de exclusão, violência e disseminação do discurso de ódio identificamos em nossa pesquisa uma importância não somente científica, de afirmação da produção historiográfica e do ofício do historiador, mas também social. Se o conservadorismo luta com a bandeira do anti-intelectualismo, Clio em sua batalha

\footnotetext{
${ }^{5}$ Disponível em: <https://anistia.org.br/direitos-humanos/informes-anuais/ > Acesso em: 06/05/2020.

${ }^{6}$ Disponível em: < https://grupogaydabahia.com.br/2018/01/18/brasil-campeao-mundial-de-crimes-lgbtfobicos/> Acesso em: 06/05/2020.

${ }^{7}$ Disponível em: < https://anistia.org.br/campanhas/jovemnegrovivo/> Acesso em: 06/05/2020.
} 
convida Atena, a deusa grega da sabedoria, da guerra estratégica e da justiça para estar ao seu lado. A sobrevivência das pesquisas críticas é necessária em tempos sombrios.

\section{O Curso "Os desafios do Ensino de História em tempos de conservadorismo" reflexões sobre metodologia e sobrevivência}

Mapear os desafios do ensino de história em tempos de conservadorismo elaborando táticas de sobrevivência requer uma metodologia que esteja atenta e possa perceber os múltiplos sentidos do fazer docente e do ser professor. Como exposto anteriormente, a conjuntura em que nossa investigação se insere é marcada pelo medo e desqualificação dos profissionais da educação, em especial da área de Ciências Humanas, com grande foco nos historiadores.

Nesse terreno, o caminho metodológico proposto prescinde de afeto, de encontros acolhedores onde experiências incomunicáveis (BENJAMIN, 1994) possam ser compartilhadas. Assim sendo, como parte da pesquisa, elaboramos o curso de extensão "Os desafios do Ensino de História em Tempos de conservadorismo", cujos dados serão parcialmente analisados neste artigo.

Voltado exclusivamente para estudantes de licenciatura em História, o curso foi gratuito e teve sua inscrição realizada pela internet, com divulgação principalmente pelo facebook e pelo WhatsApp, atingindo 30 inscrições. Ao analisar os formulários dos inscritos validamos 23 inscrições, pois 07 eram de professores de História formados, fugindo assim de nosso público-alvo: licenciandos.

Dentre as 07 inscrições não validadas tínhamos 3 professores que já atuam na rede e 03 que possuíam experiência somente enquanto estagiários. Apenas 01 destes 07 não possuía, até então, nenhuma experiência na docência. A maioria deles concluiu a graduação recentemente, nos anos de 2017 ou 2018, porém havia uma professora que se graduou em 2015 e informou estar cursando mestrado em Educação. Além desta, cabe destacar que havia ainda mais uma docente na pós-graduação, pesquisando sobre Historiografia e Ensino de História no mestrado em História Social.

Recebemos também uma inscrição de um professor que relatou que, por ser estrangeiro, não pôde fazer concurso público e por isso atua na rede estadual como contratado. Ele informou ter interesse no curso, pois deseja trabalhar com Educação e 
Direitos Humanos em áreas de conflito e no Departamento Geral de Ações Sócio Educativas (DEGASE) - um órgão do Governo do Estado do Rio de Janeiro que executa as medidas judiciais aplicadas aos adolescentes em conflito com a lei. Contudo, por ele também já ter concluído a graduação, foi uma das 07 inscrições não validadas, pois não se enquadrava no público alvo do curso.

Cabe destacar que a procura do curso por professores já formados, nos indica que este é também um espaço formativo cujos profissionais que concluíram sua graduação e atuam na educação básica desejam e anseiam, o que nos fez pensar na possibilidade de uma nova turma, voltada para professores já formados. Ressaltamos aqui que na última pergunta do formulário de inscrição no curso: "Qual é sua motivação em realizar o curso?", a maioria dos professores formados e que já atuam como docentes na rede básica, respondeu que desejava atualizar/aperfeiçoar o seu ensino de História, ou seja, buscavam enriquecer sua prática docente através do curso.

No que tange às inscrições validadas temos um perfil de turma bem diverso. A maioria dos licenciandos estuda na Universidade Federal Fluminense (UFF). Cabe destacar que a orientadora da pesquisa possui uma estreita relação com os docentes do Laboratório de Ensino de História desta Universidade, bem como a bolsista da pesquisa é aluna da referida instituição. Assim sendo, acreditamos que estes fatores possibilitaram uma divulgação maior entre os estudantes de licenciatura da UFF, tornando-os maioria de inscritos no curso.

Ao todo, recebemos 13 inscrições de licenciandos da UFF, 3 da Fundação Educacional Unificada Campograndense (FEUC) e 03 da Universidade Federal do Rio de Janeiro (UFRJ). Quanto às demais - Universidade Estadual do Rio de Janeiro (UERJ), Universidade Federal do Estado do Rio de Janeiro (UNIRIO), Universidade Federal Rural do Rio de Janeiro (UFRRJ) e Universidade Estácio de Sá -, recebemos inscrições de 01 licenciando proveniente de cada uma delas. 


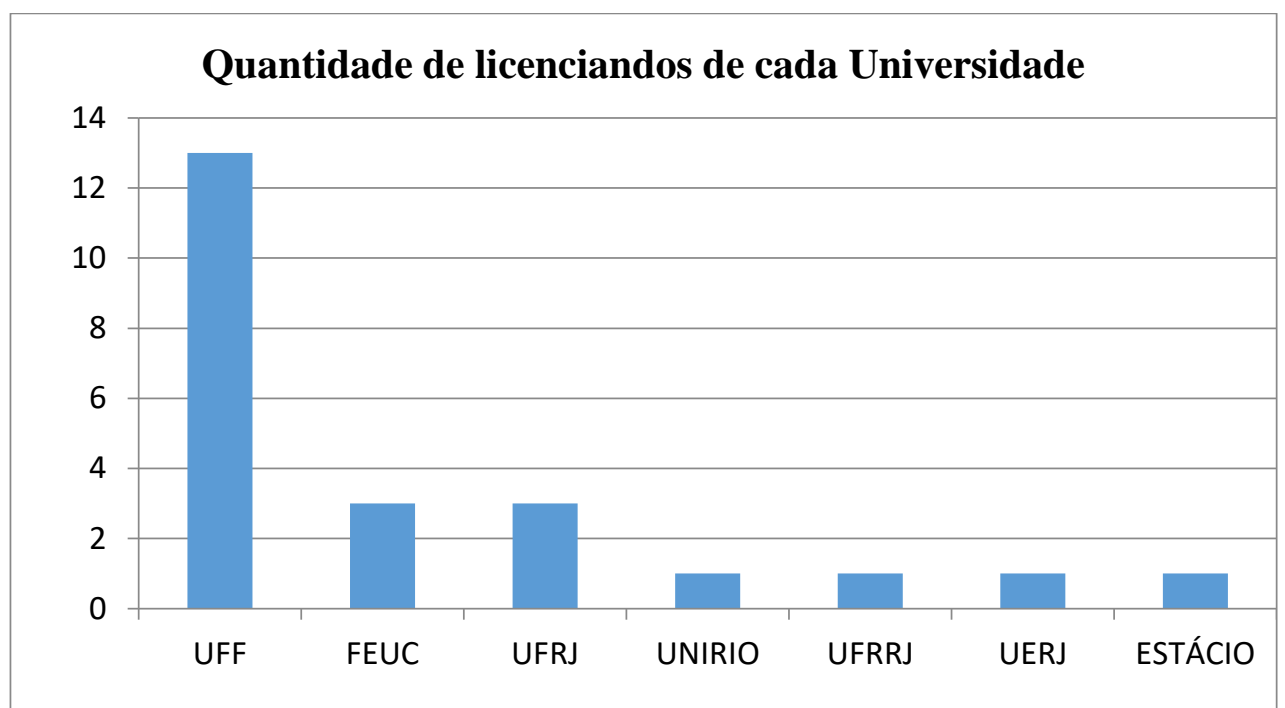

Com base no gráfico acima, podemos observar que a maioria dos graduandos inscritos é proveniente de Universidades públicas, sendo apenas 04 provenientes de instituições de ensino superior privadas. No que diz respeito à origem dos inscritos, também observamos uma heterogeneidade. A maior parte dos licenciandos (12) são moradores da Zona Norte do Rio de Janeiro. De alunos provenientes da Zona Oeste do Rio de Janeiro, recebemos 05 inscrições. Entre os 23 estudantes de licenciatura que tiveram sua inscrição validada, identificamos moradores de 14 bairros diferentes da cidade do Rio de Janeiro, além moradores de outros municípios, sendo: 02 de Niterói, 01 São João de Meriti e 01 de Guapimirim. Cabe salientar que 02 inscritos do Rio de Janeiro não informaram seu bairro. 


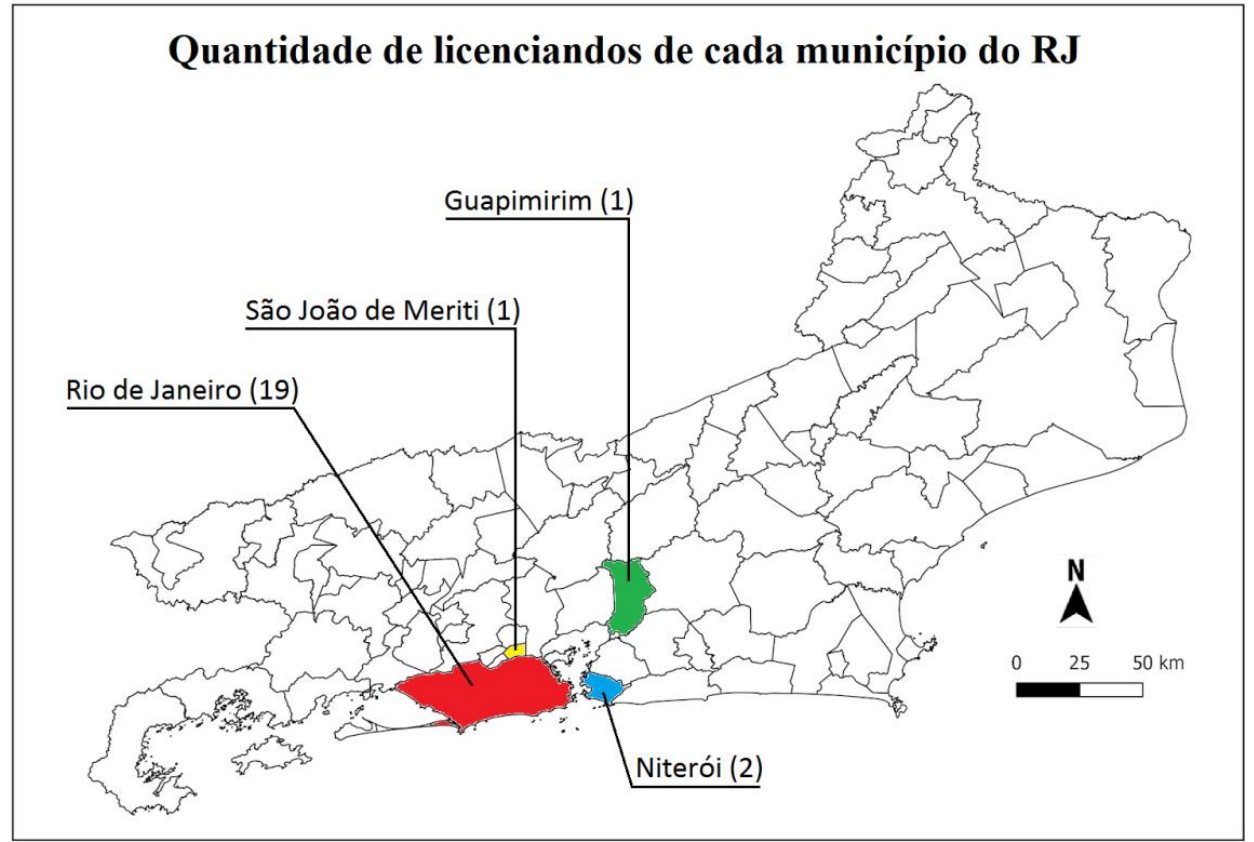

Quanto à idade, a maior parte dos inscritos estava na faixa dos 20 anos, contudo tivemos duas alunas no curso com mais de 40 anos, que estão atualmente cursando a licenciatura. No que tange ao momento em que os inscritos se encontram na graduação, a maioria informou já ter passado da metade do curso. Obtivemos 05 inscrições de alunos que se encontravam até o $4^{\circ}$ período e 18 inscrições de alunos que cursavam do $5^{\circ}$ período em diante. A respeito da experiência profissional dos graduandos, 10 informaram ter experiência somente como estagiários e 13 informaram não ter experiência alguma enquanto docente. Nesse sentido, destacamos que nenhum dos licenciandos que teve sua inscrição validada atuava como docente até então. Cabe aqui destacar que, em alguns casos, mesmo antes de se formar, estudantes de licenciatura atuam como professores em cursos preparatórios, aulas particulares ou similares.

Uma das perguntas do formulário de inscrição do curso se referia às disciplinas de estágio curricular, as quais 07 dos inscritos relataram já terem cursado. Outros 07 estavam cursando no momento e 09 informaram não terem cursado ainda. A pergunta seguinte do formulário pedia que os licenciandos contassem um pouco sobre suas experiências em sala de aula. Através de alguns relatos, pudemos observar uma certa insegurança entre os graduandos com relação à docência - especialmente devido à 
conjuntura em que se encontra o país - e também uma esperança de que o curso em questão os ajudasse nesse aspecto.

Realizei dois estágios obrigatórios numa escola particular na cidade de Maricá, onde eu residia [...] foi uma boa experiência para entender um pouco sobre o convívio com os alunos e professores: como são realizados os planejamentos de aula e avaliações, fora atividades externas e contato direto com os alunos. Apesar do estágio, ainda sinto-me crua para encarar uma sala de aula. Na época [ano de 2018], senti os alunos muito influenciados pela campanha eleitoral e bem divididos. Muitos carregando discursos feitos por seus pais, mas ainda sem uma formação própria sobre o assunto e a situação a qual estávamos passando [e ainda estamos]. Este ano encerro a graduação, mas ainda encontrome sem o amadurecimento e conhecimento de campo para me tornar uma boa professora de História e conseguir estruturar um discurso que esclareça as dúvidas sobre nossa atual situação e o impacto para o futuro da educação $\left(\mathrm{SC}^{8}\right.$, 2019).Estou estagiando no IFRJ da Senador Furtado [...] Acompanho 5 turmas de diferentes cursos técnicos, e já pude ter a oportunidade de dar uma aula, assistir conselho de classe, aula de recuperação e produzir material para a recuperação. Creio que ao encerrar, sairei com uma boa base para enfrentar os desafios que a profissão oferece, apesar de ainda estar em processo de formação. Espero que este curso me dê mais ferramentas de como lidar com o ensino da história nesses tempos sombrios (BS, 2019).

À última pergunta do formulário, os inscritos responderam de forma similar. Esta pedia que os licenciandos falassem sobre suas motivações para realizar o curso. Quase a totalidade das respostas se remeteram, basicamente, à busca por novos conhecimentos, atualização, aprimoramento profissional, formas de superação da atual conjuntura conservadora etc. A questão do conservadorismo, como fica evidente, tem pesado muito para os professores/historiadores em formação, em nossa hipótese isso se deve à desvalorização da Educação e das Ciências Humanas em especial, bem como a perseguição aos professores e censura, ainda que não explícita, de conteúdos históricos. Pensando nisso, perguntamos no formulário de inscrição se os licenciandos sentiam-se desconfortáveis ou inseguros para lecionar sobre algum tema específico e a maioria (12) respondeu que sim, alguns deles referindo-se a temas vistos como polêmicos atualmente, como assuntos relacionadas à política e questões de gênero.

Me sinto desconfortável em tratar sobre socialismo e comunismo e os alunos me associarem a "esquerdopata", entre outras denominações preconceituosas. Pois é isso, vivemos em tempos sombrios (B.S., 2019).

Ditadura militar, principalmente, por conta de retaliações de alunos e pais (N.P., 2019).

\footnotetext{
${ }^{8}$ Usaremos siglas no lugar dos nomes para preservar a identidade dos participantes do projeto.
} 
Um dos inscritos relatou ainda que já passou por uma experiência desagradável em sala de aula ao tentar dialogar com os alunos sobre assuntos como homofobia, racismo e preconceito de classe. Atentas a tal questão, decidimos adotar como exigência para a conclusão do curso que, ao final do mesmo, cada aluno elaborasse um plano de aula e material didático a respeito de algum tema considerado sensível atualmente. Em tempos de conservadorismo, precisamos tecer táticas para dialogar com os alunos e não ficarmos de mãos atadas frente às tentativas de censura e distorção de certos conteúdos historiográficos.

Contando com 5 encontros, o curso teve uma carga horária de 30 horas dividida da seguinte maneira: 15 horas de aulas presenciais, 5 horas para produção de registros das aulas em formato livre, 10 horas para elaboração de uma aula com plano de aula e material. A seguir, o cartaz usado na divulgação do curso:

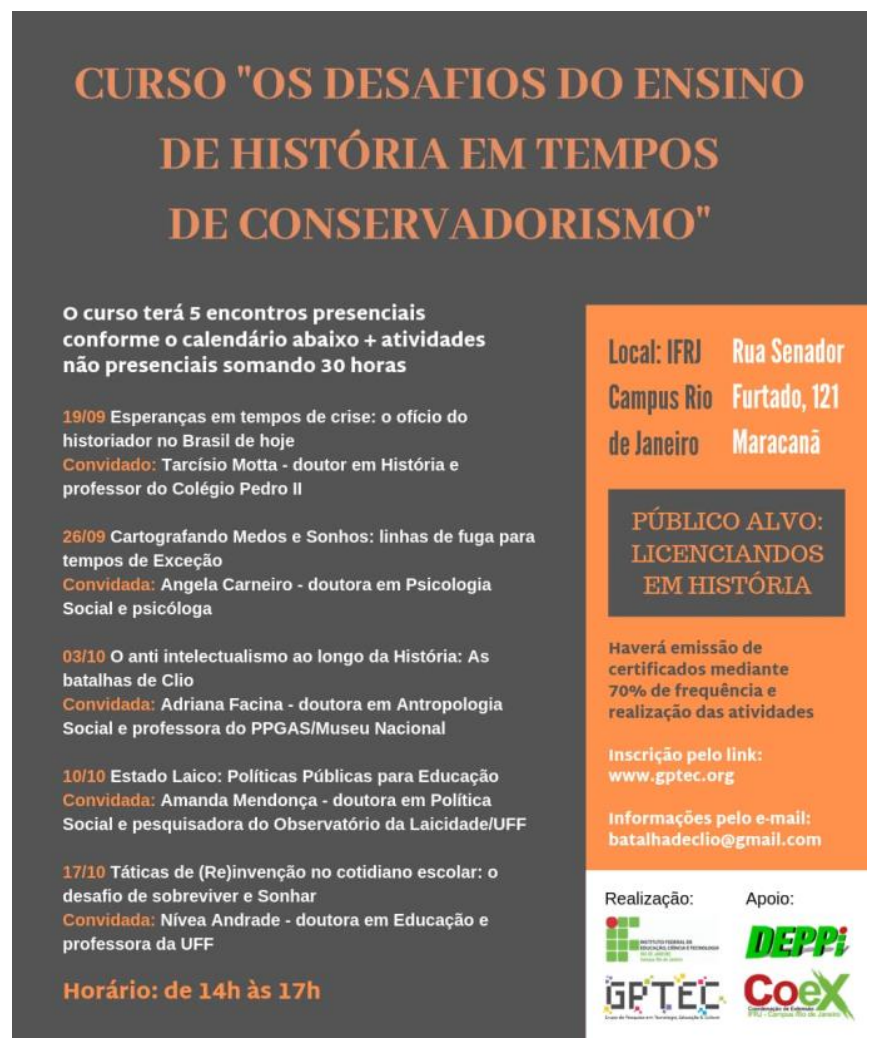

Cartaz de divulgação do curso 
Na elaboração do curso escolhemos temas que buscaram proporcionar um espaço para mapear os desafios do ensino de história em tempos de conservadorismo elaborando táticas de sobrevivência. A opção foi convidar palestrantes externos para ampliar o diálogo e permitir que a orientadora da pesquisa ficasse num lugar também de aluna/observadora, bem como a bolsista do projeto, procurando assim deixar nossos olhos e ouvidos mais livres e atentos nos encontros e produções.

Obviamente que, no papel de coordenadora que apresentou o curso e bolsista que desenvolve a pesquisa, já nos colocamos num lugar diferenciado. Contudo, ao não estar no lugar de quem conduz a aula, sentando ao lado dos alunos, buscamos construir deslocamentos não apenas nos licenciandos, mas também em nós mesmas.

Em tempos de intenso controle com filmagens e gravações não autorizadas, rejeitamos tais registros em nossos encontros. Nossa opção metodológica foi pela escuta e escrita. Assim, apenas foram tiradas fotos pontuais para memória e prestação de contas. Produzindo narrativas individuais, bolsista e coordenadora elaboraram registros próprios de cada aula, como destacamos a seguir.

Em seu artigo "Narrar ou descrever? Contribuição para uma discussão sobre naturalismo e o formalismo”, Lukács (1965) escolhe dois clássicos da literatura para, a partir da cena de uma corrida de cavalos, problematizar as distinções entre o ato de narrar e o de descrever. Naná, de Zola, e Ana Karenina, de Tolstoi, servem de inspiração ao autor em sua afirmação de que a descrição parte do ponto de vista do espectador/observador, enquanto a narração implica o olhar da participação.

O contraste entre o participar e o observar não é casual, pois deriva da posição de princípio assumida pelo escritor, em face da vida, em face dos grandes problemas da sociedade, e não do mero emprego de um diverso método de representar determinado conteúdo ou parte do conteúdo (1965, p.50).

Dialogando com a observação de Lukács, nós participamos deste processo e nos implicamos com ele. Ao longo das cinco aulas do curso, produzimos nossas narrativas destes encontros e destacamos alguns trechos para análise:

Ao longo da [primeira] aula falamos sobre o rigor do professor de História, da necessidade de ter cuidado para não avaliar o aluno a partir das nossas opiniões e sim de conceitos históricos sólidos trabalhados em sala e nos materiais. 
Dialogamos também sobre o perigo da autocensura em tempos de conservadorismo (P.P., 2019).

A aula inaugural do curso, com o professor Tarcísio Motta ${ }^{9}$ foi muito proveitosa e fomentou diversas discussões pertinentes acerca do ofício do historiador no Brasil de hoje. Tarcísio abordou autores como Paulo Freire, Walter Benjamin, Thompson e Gramsci para afirmar a importância do "Esperançar" e de o professor realizar em sala de aula uma "desnaturalização do presente". Ou seja, cabe ao historiador perceber e mostrar que a história que conhecemos hoje se deu dessa forma por determinados motivos e a história que virá não é predeterminada. Portanto, podemos ser sujeitos ativos de sua escrita se conseguirmos enxergar na história outras possibilidades.

Para tal tarefa, é necessário que o professor saiba dialogar com os alunos acerca de temas considerados polêmicos atualmente, a fim de chamar atenção para a história que não é oficial, de incentivar o pensamento crítico dos mesmos acerca de temas cristalizados ou silenciados. Sendo assim, devemos estar atentos ao perigo da autocensura, como foi citado no fragmento acima.

A aula da psicóloga Angela Carneiro me tocou profundamente, eu chorei do
início ao fim. A aula me afetou profundamente. O conceito de afeto foi
trabalhado pela psicóloga nos fazendo refletir sobre o quanto nos deixamos
afetar pelo outro, pelas experiências do dia a dia, e sobre o quanto temos nos
fechado para esse afeto [...] Ela também trabalhou conosco a questão corporal,
nos levando [...] a repensar a relação que estabelecemos com nossos corpos
[...] Essa aula para mim - e creio que para todos os presentes - representou
justamente uma fuga dessa rotina maçante e massificante, um momento de
transgressão, de afeto, de superação de medos e esboço de sonhos. (L.G., 2019)

A questão corporal abordada por Angela ${ }^{10}$ no segundo encontro do curso se referia à necessidade da percepção do corpo na sala de aula, a qual nos remete à separação entre corpo e mente que Bell Hooks critica:

Com efeito, a objetificação do professor dentro das estruturas educacionais burguesas parecia depreciar a noção de integridade e sustentar a ideia de uma

\footnotetext{
${ }^{9}$ Tarcísio Motta é professor de História do Colégio Pedro II, possui doutorado em História pela Universidade Federal Fluminense e atualmente é vereador na cidade do Rio de Janeiro.

${ }^{10}$ Angela Carneiro é professora, psicóloga clínica e educacional. Fez estágio de Pós doutorado pelo Programa de Pós-Graduação em Psicologia na Universidade Federal Fluminense-UFF.
} 
cisão entre mente e corpo, uma ideia que promove e apoia a compartimentalização (2013, p. 29).

Buscando fugir desta separação entre mente e corpo nos mexemos bastante em nossos 05 encontros. As aulas do curso foram marcadas por muita troca, atenção e afeto. Cabe destacar que o clima presente não era de medo ou desânimo, mas sim de apreensão, que ao ser levado e discutido no coletivo foi se diluindo. A segunda aula, como expresso no relato acima, foi marcada por muitos afetos, quase todos os participantes se emocionaram em alguma parte. Ao final da aula, no momento de uma breve reflexão/avaliação sobre o encontro, as palavras mais repetidas eram "gratidão", "obrigada", "essa aula mexeu muito comigo", demonstrando assim a importância do tema do afeto e da escuta na formação de professores.

A terceira aula também não foi diferente, inclusive a própria palestrante, Adriana Facina $^{11}$, se emocionou em diversos momentos e foi conduzindo o debate para afirmar a urgência de criarmos táticas de sobrevivência em momentos de anti-intelectualismo.

Dialogando com a obra de Hannah Arendt A banalidade do mal Adriana Facina nos relembra que o nazismo precisou de gente para operar o sistema, mas também para silenciar. E a partir disso ela apresenta a ideia de vazio de pensamento, do "cumprir ordens" e como isso é totalmente oposto ao pensamento crítico, por exemplo defendido por Paulo Freire, daí ele ser tão odiado pelos segmentos conservadores (P.P., 2019).

O quarto encontro do curso trouxe como recursos charges e reportagens jornalísticas que nos permitiram debater as dificuldades e entraves para prática da Educação Laica em nosso país. Apresentando de forma sistematizada as diferentes concepções de Estado Laico, bem como sua distinção de Estado Ateu este encontro possibilitou que muitas dúvidas pudessem ser compartilhadas e sanadas.

\footnotetext{
11 Adriana Facina é professora do Programa de Pós-Graduação em Antropologia Social/Museu Nacional/UFRJ e do Programa de Pós-Graduação em Cultura e Territorialidades/UFF. Possui graduação e mestrado em História tendo sido professora de História Contemporânea na Universidade Federal Fluminense (UFF).
} 
Amanda Mendonça ${ }^{12}$ instigou a turma a refletir sobre o que é um Estado Laico, apresentando algumas definições do senso comum, desmistificando-as, e abordando a definição com a qual trabalha junto ao Observatório da Laicidade na Educação [...] o debate foi muito rico, constituindo, a meu ver, talvez o momento de maior participação da turma durante o curso, foram muitas experiências e opiniões trocadas e, pelo menos de minha parte, muitos conhecimentos adquiridos (L.G., 2019).

O constante debate permeou todos os encontros do curso, não foram raros os dias em que nos perdíamos na hora ficando o desejo de mais tempo para continuarmos aquela temática. Sentimento este que foi bastante presente na última aula do curso, ministrada pela professora Nívea Andrade. Mexendo com nossos corpos e mentes, a também historiadora e professora de Ensino de História da Faculdade de Educação da UFF encerrou o curso de forma extremamente potente.

\begin{abstract}
Nívea começou a aula já propondo uma atividade diferente [...] o 'teatro imagem', criado pelo teatrólogo Augusto Boal em seu livro Teatro do Oprimido, na qual dois alunos deveriam moldar os corpos de outros três (ou quantos se voluntariassem) para formar uma cena, sem que houvesse comunicação entre os dois grupos. Nívea propôs que a temática da cena fosse uma sala de aula de História numa escola pública do Rio de Janeiro (L.G., 2019).
\end{abstract}

Esse foi um momento de muita descontração, de muita troca e participação da turma. Todos contribuíram, inicialmente, tentando adivinhar do que se tratava a cena e, posteriormente, dando suas opiniões acerca de como seria a sala de aula ideal e como poderíamos atingi-la. Todos se divertiram com o processo de montagem da cena, uma vez que o mesmo produziu situações engraçadas, apesar de desconfortáveis de início. Isso porque não somos acostumados a ativar nossa corporalidade nos ambientes educacionais.

Neste sentido, tal atividade e as similares empreendidas no segundo encontro do curso foram um momento de entusiasmo na sala de aula e de transgressão de fronteiras, ao passo que foram além das barreiras socialmente construídas que ditam os comportamentos nos ambientes acadêmicos e colocaram os alunos e seus corpos como parte ativa do processo de ensino-aprendizagem. Nesse sentido, tais aulas foram também

\footnotetext{
12 Amanda Mendonça é professora Universitária, Pós-doutoranda em educação na Universidade Federal Fluminense (UFF), doutora em Política Social e mestre em educação. Integra o Observatório da Laicidade na Educação como pesquisadora.
} 
momentos de elaborações de táticas de sobrevivência nas escolas em tempos de conservadorismo.

Como aponta Nívea Andrade ao pesquisar sobre cotidiano escolar, se os profissionais da educação em seu dia a dia não dominam as estratégias de alteração do status quo, visto que estas lhes são impossíveis pois só pertencem aos grupos dominantes, o chão da escola é o lugar das táticas ${ }^{13}$. A autora reconhece que as táticas não são revolucionárias na medida em que não conseguem transformar o estatuto do poder, tão pouco retirar determinados grupos de seu lugar de privilégio, no entanto, as táticas usadas podem obrigar os que estão no poder a reformularem permanentemente suas estratégias e nesse sentido, são transformadoras das relações sociais (ANDRADE, 2011).

\section{Considerações finais}

Imbuídos do objetivo de diagnosticar inseguranças e medos em relação à docência em História nos tempos atuais procuramos criar, a cada encontro, uma relação de confiança e afeto com esses alunos-mestres para que assim possamos elencar temas históricos que podem ser vistos como "polêmicos" frente ao discurso conservador em voga atualmente. Assim, compreendendo o papel social dos Institutos Federais, em especial das Ciências Humanas nestas instituições (MONTEIRO; PASSOS; LIMA, 2018) pretendemos a partir dos levantamentos feitos neste curso, elaborar materiais didáticos voltado para o público do Ensino Fundamental e Médio sobre os temas elencados pelos alunos como "sensíveis" na conjuntura conservadora atual.

Almejamos no curso de extensão oferecido e neste artigo, refletir acerca do papel do Ensino de História no combate às desigualdades históricas de nosso país, afirmando sua importância na formação de um cidadão crítico. Parafraseando o poeta Vinicius de Moraes para quem "A vida é a arte do encontro embora haja tantos desencontros pela vida" apostamos na metodologia dos encontros com esses alunos-mestres para criar essas táticas e assim praticar o "Esperançar" defendido por Paulo Freire (1992). Em cada encontro, dinâmicas, músicas, poemas, leituras, discussões e produções escritas serviram como táticas de superação dos medos e conservadorismos que nos assombram nos dias de hoje.

\footnotetext{
${ }^{13}$ A autora referencia-se nas teorias de Michel de Certeau (2012)
} 


\section{REFERÊNCIAS}

ACSELRAD, Henri. Espectros do anti-intelectualismo tropical. Le Monde Diplomatique Brasil. 2018. Disponível em: <https://diplomatique.org.br/espectros-doanti-intelectualismo-tropical/> . Acesso em 12/04/2019.

ANDRADE, Nívea. Práticas escolares como táticas criadoras: os praticantes nas tessituras de currículos. 2011. 153f. Dissertação (Doutorado em Educação) - Programa de Pós-Graduação em Educação, Universidade do Estado do Rio de Janeiro, Rio de Janeiro.

Anistia Internacional. Anistia Internacional- Informe 2017/18. 2018. Disponível em <https://anistia.org.br/wp-content/uploads/2018/02/informe2017-18-online1.pdf>.

<https://anistia.org.br/campanhas/jovemnegrovivo/>.

Campanha Jovem Negro Vivo. Disponível em

ARRIGHI, Giovanni. O longo século XX: dinheiro, poder e as origens do nosso tempo. Trad. de Vera Ribeiro. Rio de Janeiro: Contraponto; São Paulo: Editora da Unesp, 1996.

BENJAMIN, Walter. Magia e técnica, arte e política: ensaios sobre literatura e história da cultura. São Paulo: Brasiliense, 1994. - Obras escolhidas volume 1.

BLOCH, Marc Leopold Benjamin. Apologia da História, ou, O Ofício do Historiador. Rio de Janeiro: Jorge Zahar Ed., 2001.

CERTEAU, Michael de. A invenção do cotidiano: 1. Artes de fazer. Petrópolis, RJ: Vozes, 2012.

FREIRE, Paulo. Pedagogia da esperança: Um reencontro com a pedagogia do oprimido. Notas de Ana Maria Araújo Freire. São Paulo, Editora Paz e Terra, $3^{\text {a }}$ ed. 1992.

HOOKS, Bell. Ensinando a transgredir: A educação como prática da liberdade. São Paulo: Editora WMF Martins Fontes, 2013.

LUKÁCS, Georg. Ensaios sobre literatura. Rio de Janeiro: Civilização Brasileira,1965.

MONTEIRO, Evelyn Morgan; PASSOS, Pâmella; LIMA, Vinícius Carvalho. O lugar das Ciências Humanas em um Instituto Federal: narrativas cotidianas. In: PEREIRA; Marcus Vinicius; ROÇAS, Giselle (Org.). As nuanças e o papel social dos institutos federais de educação, ciência e tecnologia: lugares a ocupar. João Pessoa: IFPB, 2018.

PASSOS, Pâmella. Vozes a favor do golpe! O discurso anticomunista do Ipês como materialidade de um projeto de classes. Rio de Janeiro: Editora Mórula, 2017. Disponível em: <http://www.gptec.org/acervo/VozesAFavorDoGolpe.pdf>. Acesso em: 29 mar. 2019 . 
PENNA, Fernando. O ódio aos professores. In: Ação Educativa Assessoria, Pesquisa e Informação (Org.). A Ideologia do Movimento Escola Sem Partido. São Paulo: Ação Educativa, 2016.

SEPULVEDA, Jose Antonio \& SEPULVEDA, Denize. O pensamento conservador e sua relação com práticas discriminatória na educação: a importância da laicidade. Revista Teias, v. 17 - n. 47 p. 141-154. 2016. 